\title{
Learning from Both Sides: Experiences and Opportunities in the Investigation of Australian Aboriginal Medicinal Plants
}

\author{
Bradley S Simpson ${ }^{1,2}$ David J Claudie ${ }^{3}$ Nicholas M Smith $^{4}$, Ross A McKinnon ${ }^{1,2}$, Susan J Semple ${ }^{2}$ \\ ${ }^{1}$ Flinders Centre for Innovation in Cancer, Flinders University, Bedford Park, South Australia, Australia; ${ }^{2}$ University of \\ South Australia, Adelaide, South Australia, Australia; ${ }^{3}$ Chuulangun Aboriginal Corporation, Cape York Peninsula, \\ Queensland, Australia; ${ }^{4}$ Nelumbo Botaniks, Aldinga Beach, South Australia, Australia
}

Received, March 15, 2013; Accepted, June 9, 2013; Published, June 10, 2013.

\begin{abstract}
With one of the oldest surviving cultures in the world, Australian Aboriginal people have developed immense knowledge about the diverse Australian flora. Western scientific investigation of some Australian Aboriginal medicinal plants has demonstrated interesting pharmacological activities and chemistry, however the majority of these species have not yet been extensively examined. We argue that research that is locally initiated and driven by Indigenous traditional owners in collaboration with Western scientists has significant potential to develop new plant-based products. Locally driven medicinal plants research in which traditional owners work as researchers in collaboration with University-based colleagues in the investigation of medicines rather than "stakeholders" or "informants" is one model that may be used in characterising plants with the potential to be developed into sustainable plant-based medicinal products with commercial value. Our team has taken this approach in research located both on traditional homelands and in the laboratory. Research being conducted by the University of South Australia and Chuulangun Aboriginal Corporation has led to patent filing for protection of intellectual property associated with novel compounds and extracts with the potential for development through cosmetic, complementary medicine and pharmaceutical routes. Ongoing research is examining the commercial developmental pathways and requirements for product development in these spaces. This review will address the opportunities that might exist for working in partnership with Australian Indigenous communities, some of the scientific knowledge which has been generated so far from our work together and the lessons learnt since the inception of the collaboration between the Chuulangun Aboriginal Corporation and scientists from the University of South Australia.
\end{abstract}

This article is open to POST-PUBLICATION REVIEW. Registered readers (see "For Readers") may comment by clicking on ABSTRACT on the issue's contents page.

\section{INTRODUCTION}

This article provides a philosophical and cultural perspective of an Australian based Indigenousguided natural product medicine project, which is complemented with a discussion of some of the Western scientific research outcomes. The reader should note that aspects of the discussion included in this manuscript may not necessarily reflect the beliefs and opinions of individual (specific) Australian Aboriginal communities but should rather be viewed as a broader, more generalized perspective.

Australian Indigenous peoples have occupied the Australian continent for an estimated 40,00050,000 years (1) and during that time have developed a profound understanding of the Australian landscape and processes of biodiversity conservation management. At the time of European settlement in 1788, early explorers were surprised at how such a landscape had been kept curated in an almost pristine-like manner (2). Complex traditional land management practices used by Indigenous peoples helped to create the natural landscape of Australia prior to European arrival (3-6). Unfortunately, as Western agricultural practices and population increase began to take effect, so did an imbalance of the once well-managed country (homelands).

In some regions of remote Australia, the influence of Western society and governance has resulted in a shift in the number of Indigenous people living on traditional homelands, with many relocating to major urban centres, resulting in a loss of heritage and traditions of their ancestors (7). Ultimately, this will lead to a decline in the

\footnotetext{
Corresponding Author: Bradley Simpson, Flinders University, School of Medicine, Mailing address: Adelaide, South Australia, Australia, 5001; Email: bradley.simpson@flinders.edu.au
} 
intergenerational transfer of traditional knowledge that has been developed and maintained over the millennia. While it may not be immediately apparent, a failure to address this issue has consequences for Aboriginal peoples in terms of a loss of language, culture and identity (8). Moreover, traditional management practices which have sustained the unique biodiversity that exists today on the Australian continent will also be threatened $(6,9,10)$.

Traditional medicine systems form one aspect of Australian Indigenous traditional knowledge. It should be noted that these systems are highly complex and may vary between different Indigenous groups across the continent (11-13). These systems incorporate mostly the use of plants for the purpose of treating disease but may also see the use of other natural resources (e.g. animals such as Witchetty grub, Endoxyla leucomochla and minerals and clays) (12-14). Traditionally there has been oral transmission of this knowledge (and traditional knowledge in general) which may come in the form of stories, singing and dancing ceremonies. Due to an absence of a written language, physical recordings of this knowledge prior to European colonisation of Australia do not exist. Therefore traditional owner groups are undertaking and exploring ways to preserve knowledge. One possible way is through collaborative projects with Western-based researchers working in areas of botany, ecology, pharmacology and anthropology to record knowledge and investigate plants from a Western scientific perspective for pharmacological activity.

This review will address the opportunities that might exist for developing medicinal products from the Australian flora and working in partnership with Australian Indigenous communities. Our own experiences of working in an ongoing collaborative research initiative between Indigenous researchers based on their traditional homelands in Cape York Peninsula, Queensland and University-based researchers will be presented. An emphasis is placed on reviewing the Western scientific outcomes from this research to highlight the therapeutic opportunities that exist in the investigation of Australian Aboriginal medicinal plants in addition to preserving medicinal plant knowledge.

\section{The Opportunity}

Australia is listed as one of the Earth's megadiverse countries by Conservation International and the United Nations Environment
Program's World Conservation Monitoring Centre. Fire regimes have been a major tool to ensure a balance and survival of the approximate $18,500( \pm 1.0 \%)$ native flowering plant species that are found in Australia (15). Australia possesses one of the highest levels of species richness and endemism in the world. Areas containing both species richness and endemism are classified as hotspots, with several having been identified by Crisp et al. (16) from work reported during the early 2000s. These include south-west Western Australia, Cape York Peninsula (Queensland), Border-Ranges (Queensland - New South Wales border), North Kimberly, Kakadu-Alligator Rivers (Northern Territory), Kangaroo Island (South Australia) and Tasmania. With such rich biodiversity, the notion that this could translate into novel chemical diversity of natural products produced by these plants with biological activities that are unique in their mode of action is a tantalising prospect.

Many plants have been used by different clans of Indigenous people throughout Australia as a means of primary treatment of ailment and disease. Whilst Indigenous populations rely on access to conventional (Western) medicines, the use of more traditional approaches remains. One important distinction between Western and Traditional medicine is the philosophy behind how the illness and disease is combatted (17). Indigenous philosophy as it relates to medicinal plants sees the whole plant (or plant part) and the combination of constituents found within it as the active ingredient, in contrast to Western medicine, where generally a single chemical entity is used as the medicine $(14,18,19)$.

It would be a disappointing scenario if the knowledge of medicinal plant use developed by Australian Indigenous populations was lost. The opportunity to help ensure that this information is available for generations to come and work with communities in achieving this would be foolish to ignore. Before such ventures can take place however, an understanding is required to realise why communities might not want to work with Western researchers.

Part of the reluctance of indigenous communities to work with Western scientists is historical and relates to the post-colonisation treatment as non-equal, including the removal of Indigenous populations from their native lands and into Government controlled reserves initiated by Aboriginal Protection Acts (e.g. The Aboriginals Protection and Restriction of the Sale of Opium Act 1897) (20). In terms of medicinal 
plant research in the contemporary setting, there are two aspects to consider. The first of these relates to the recording of traditional knowledge in the public domain. Whilst we are proponents to approaches which help to preserve traditional knowledge as it relates to Indigenous medicinal plants use, publishing such works into the public domain, does raise the question of whether this could indeed be detrimental to communities in the long-term. While in many cases this may have been done with good intentions (i.e. to preserve knowledge in written form), researchers may use this knowledge without talking to, or recognising the owners of the knowledge or return of benefits to the communities to which the genetic resources belong (21). An important factor to consider in relation to this is where Indigenous people stand on their intellectual property rights once information is released into the public domain. One option for overcoming this challenge is develop initiatives which restrict public access to recorded traditional knowledge so that Indigenous people benefit by legally protecting their knowledge (in accordance with Western legal systems) as well as recording it for the betterment of future generations. The second aspect relates to the scientific testing of plants and medicinal product development that is based upon traditional knowledge, where outcomes are published without Indigenous involvement or acknowledgement. This precedence has made it somewhat more challenging to establish collaborative research ventures for new groups as a result of a lack of trust towards outsiders and western researchers (22).

In recent years, there has been a positive shift towards creating collaborative research initiatives with Indigenous communities in which all parties participate and benefit. This is most likely as a result of the establishment of the Convention on Biological Diversity and the subsequent protocols and guidelines governed by this instrument both abroad (e.g. Bonn Guidelines (23), Nagoya Protocol (24)) and locally (25). Whilst it is common for Western researchers to want to learn from Indigenous peoples, there is a strong desire of Indigenous communities wanting to understand what Western scientific principles can tell them about their natural resources and how this knowledge might be harnessed for the benefit of their people. A two-way exchange of information approach is helping to move beyond the dichotomy of Indigenous versus scientific paradigms that has plagued the area for a long time (26). In constructing collaborative research with Indigenous people, it should be made apparent that traditional knowledge is Indigenous technology (2). Accordingly, Indigenous people have their own effective science and resource use practices; a concept that is finally gaining practical recognition (27).

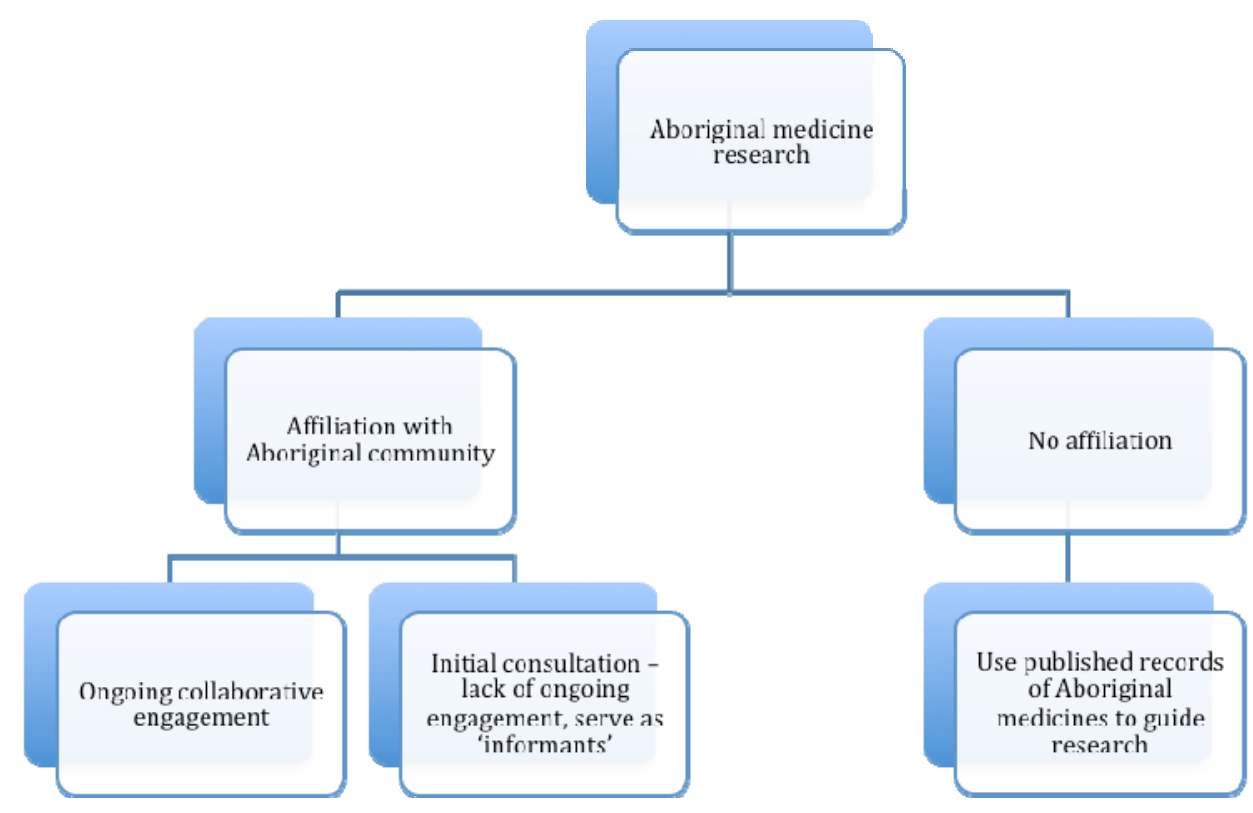

Figure 1. Approaches to Aboriginal medicine research in Australia. 


\section{Previous Medical Plant Research in Australia}

Research centred on the Western scientific properties of Australian Aboriginal medicinal plants, namely the chemistry, pharmacology and mode of actions has been predominantly carried out within academic institutional environments. Figure 1 illustrates general pathways for researching Australian Aboriginal medicines, being either affiliated or non-affiliated with an Indigenous community(ies).

Some of the earliest research carried out on Australian flora was initiated by the CSIRO during the 1940s in response to World War II and the need to find sources for new drugs of plant origin at the time (28). Several thousand plant species were screened for their alkaloid content over an approximate 30 year period and subsequent screening for anti-tumour activity as part of an agreement with the Cancer Chemotherapy National Service Centre, National Institutes of Health (USA). Alkaloid secondary metabolites as stock poisons or with anti-tumour activities were of major interest to the CSIRO. However, a loosely organised collaboration of phytochemists from Australian universities stemming from this initiative were involved in identifying a broad range of other chemical classes including terpenoids, flavonoids, steroids and other phenolics. Many of the compounds were isolated and identified for the first time highlighting the novel chemical diversity of natural products produced by the unique Australian flora. However, in general these studies lacked any pharmacological aspect. Needless to say, therefore, the chemodiversity and pharmacological potential of the large number of plant species screened was still far from understood.

There are still a large number of plants used by Australian Indigenous communities for medicinal purposes (either recorded in the literature or not in the public domain) that have not been examined from Western scientific perspectives. Previous projects like the CSIRO type and other more recent ones (29) involved little if any consultation with Indigenous communities. Hence opportunities remain for current and future research projects to operate as collaborative, ethnobotanical-guided initiatives to discover a wealth of untapped potential from traditionally used plants.

Some research approaches may involve use of published literature sources and Aboriginal pharmacopoeias as a means guiding of plant selection for Western scientific studies of the native flora (30-34). This form of research, which has been undertaken in the past by some of the authors of this review, is driven and published purely by Western researchers with little, if any scope for this avenue to provide benefits back to the communities whose knowledge, culture and spirituality are embedded in those resources. Alternatively, where an affiliation initially exists, this may be short-lived for a variety of reasons with Indigenous peoples then simply serving as informants of traditional knowledge which guides the research, and become bystanders of the research process as Western researchers continue to carry on their investigations (35). Another approach can be research collaborations that are initiated and driven by the Indigenous communities themselves and that are in line with local aspirations for natural resource management and preservation of traditional knowledge.

There are a number of Australian Aboriginal traditional owners who are striving hard to better their communities' livelihoods through the initiation of different ventures which capitalise on the strengths of 'living off the land'. The Australian Human Rights Commission in its 2010 Social Justice Report, acknowledges the economic viability of homelands and particularly resource management projects which generate opportunities for conservation and economic development for traditional owners living on homelands (36). On homelands there is an enormous potential for traditional owners to develop economic opportunities based in sustainable land and resource management which includes river and water management, biodiversity conservation, carbon sequestration, fire control, quarantine, ecotourism and sustainable harvest of plant products. Such land management based activities are sometimes referred to as belonging to the 'conservation economy' or 'hybrid economy' which supports Aboriginal aspirations to live and work on country (37).

We argue that traditional owners of this calibre and who have relevant vision and foresight will have a greater bearing on the survival of their culture and identity than will Western researchers simply wanting to test plants based on valuable traditional ecological knowledge without research partnerships and the sharing of benefits.

Before discussing the collaborative project to which the authors of this review belong, it should be highlighted that there are other academic groups in Australia who are involved in 
innovative Indigenous engagement research activities where medicinal plants and knowledge are of central focus. One such group includes researchers from the Indigenous Bioresources Research Group at Macquarie University, New South Wales who work with Aboriginal communities of Northern New South Wales (38). Part of the strategy for collaborating with Indigenous people from this area of Australia is stimulated by the fact that there has been little focus on New South Wales communities in previous studies which have documented the preparation and use of medicinal plants of Australian Aboriginal communities (39). A strong emphasis of the groups work is centred on the detailed recording of ethnobotanical data from communities within this region as a means of preserving the invaluable customary medicinal knowledge of these people (40). Additionally, they have also developed educational activities for school children in these areas as part of an initiative know as Indigenous Science Education Program (ISEP) (41).

A partnership between researchers from Griffith University and members of The Jarlmadangah Burru Aboriginal Community from the Kimberly region, North Western Australia has developed agreements on access and benefitsharing arrangements. This research partnership, has resulted in filing of a patent co-owned by each party for the protection of the intellectual property relating to novel analgesic compounds isolated from a plant traditionally known as the Marjala plant (Barringtonia acutangula) $(42,43)$.

\section{Kuuku I'YU Medicinal Plant Project}

The homelands of Kuuku I'yu Northern Kaanju people are located in Cape York Peninsula, Queensland, Australia and encompass some 840,000 hectares. Their country is centred on the upper Wenlock and Pascoe Rivers and is bordered by Archer River in the South, extending to Olive River in the North and from Lockhart Valley in the East, stretching to Embley Range in the West. For Kuuku I'yu Northern Kaanju people simply being partners or stakeholders in land and resource management projects run by mainstream agencies is not adequate. Instead they strive for a more locally driven and self-determined approach to the way in which they manage their land and resources (44). The origins of the collaboration between Chuulangun Aboriginal Corporation and University of South Australia researchers has in part been built on a reformed model of natural resource management (NRM) practices developed by The Corporation (44) (See Figure 2). One area of prioritisation in this framework is centred on the sustainable use and development of traditionally used medicinal and aromatic plants. To achieve these priorities Northern Kaanju traditional owners invited Western researchers to join them in initiating projects that would investigate the chemical and pharmacological properties of plants used in the traditional medicine system of Kuuku I'yu Northern Kaanju ancestors.

The manner by which this project was established often gives a reaction of surprise by outsiders due to the unusual situation of Indigenous researchers initiating partnerships with Western researchers, rather than by Western researchers. It is this contrasting approach however that is leading to novel Western scientific knowledge and understanding of these resources and treading new territory in terms of the recognition and benefits being distributed back to the community.

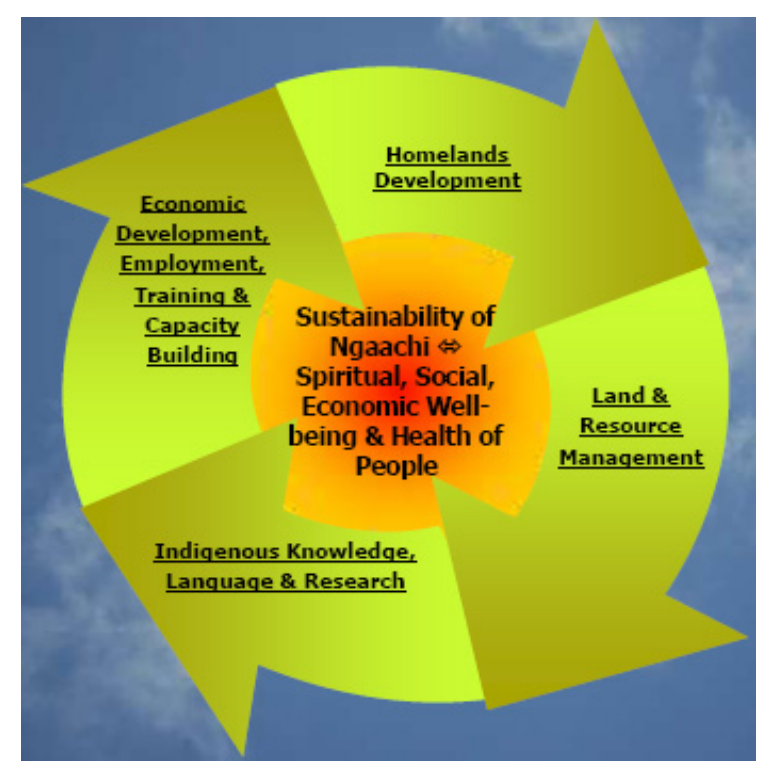

Figure 2 Model for Sustainable Natural Resource Management (NRM) on Kuuku I'yu Northern Kaanju traditional homelands. (Reproduced with permission from Chuulangun Aboriginal Corporation).

The development and intellectual property considerations of this collaborative research model as one approach for Indigenous-initiated and driven Australian medicinal plant research has been covered in detail elsewhere (35). 
The remainder of this review will examine the findings of the Western-science from this work, how it complements the Indigenous science (traditional knowledge) of the plants investigated (as opposed to confirming/dismissing the validity of the knowledge) and what it means in terms of moving forward.

As part of an Australian Research Council Linkage grant (2006-2009), several plants collected from Kuuku I'yu Northern Kaanju homelands were screened for their antiinflammatory properties using an acute mouse ear oedema model (male Balb/C mice). This particular model uses the tumour-promoting phorbol ester 12-O-tetradecanoylphorbol-13acetate (TPA) to induce inflammation of the ear. It is characterised by a marked increase in redness and swelling, where ear thickness is measured as an endpoint for inflammation (45). The model allows the detection of anti-inflammatory compounds that work by a variety of different mechanisms. Amongst the most active antiinflammatory extracts tested in this model was a sample prepared from the leaves and stems of the plant Dodonaea polyandra. The traditional use of D. polyandra (known traditionally as 'Uncha' by Kuuku I'yu traditional owners involved in the project) is to counteract pain, inflammation and discomfort associated with toothache and infection in the oral cavity. The laboratory in vivo result complemented the traditional use of Uncha. Ethanol was used as the initial extraction solvent for laboratory testing due to its ability to extract a broad range of plant secondary compounds. Traditionally the plant was not prepared as an extract but the plant material was used directly held in the mouth, chewed or inserted into the hole following the removal of a tooth. This type of application could allow the release of a range of both lipophilic and more hydrophilic compounds into the saliva.

The initial Western scientific results with extracts of $D$. polyandra consequently stimulated several years of intense research to uncover the chemical and mechanistic basis of the observed effect. To begin establishing the class(es) of constituents found in Uncha that might be responsible for this effect an activity-guided approach was undertaken. This technique which is widely used in natural products isolation, involves fractionating the extract based on the polarity of the constituents then testing fractions for bioactivity. Active fractions can be further separated and tested and pure active compounds eventually isolated. In vivo screening of solvent fractionated samples of $D$. polyandra ranging from low to high polarity was conducted. The results from this work (46) suggested secondary metabolites of non-polar nature were major contributors to the overall activity, whilst more polar constituents were contributing to a lesser extent. Activity-guided fractionation was conducted on lipophilic extracts of $D$. polyandra leaves in the same mouse ear oedema model of acute inflammation. The bioactivity was concentrated to within a small number of subfractions obtained from chromatographic separation processes of the extract. Eventually, four benzoyl ester furanoclerodane diterpenoids were isolated, of which three were established as contributing a major part of the anti-inflammatory effects of the plant (47).

The activity profiles for these compounds were determined via dose-response relationships, which revealed non-linear (biphasic) characteristics. The mechanism behind this phenomenon is often difficult to ascertain due to the multivariate nature of the response. However, such responses have potential to suggest possible molecular mechanisms for the compounds by noting other types of compounds known to give similar responses. Interestingly, glucocorticoid steroids are noteworthy examples known for displaying biphasic dose-response curves $(48,49)$.

Whilst the full understanding behind the molecular mechanism of action of glucocorticoids is far from complete, it has been suggested that their ability to cause transrepression (transcription repression) and transactivation (transcription activation) of both pro- and anti-inflammatory genes (eg. cytokines and their receptors) could in part explain these trends (50-52). Understanding the mechanism of action of these diterpenoids compounds has been a primary focus of the most recent research due to initiation of commercial development pathways (see later). Understanding the chemical nature of the active compounds from a Western-scientific perspective was all very interesting, however traditional knowledge philosophy states that the effect is due to the whole plant (ie. all the constituents) and not a few single chemical entities. It is also viewed traditionally that disturbing the balance (ratio) of constituents can lead to the plant losing pharmacological effects. As mentioned above, this research is grounded in complementing the traditional knowledge and use of medicinal plants within the Kuuku I'yu traditional medicine system rather than proving it right or wrong. 
<smiles>C[C@H]1[C@H](COC(=O)c2ccccc2)CC[C@H]2C(C(=O)O)=CCC[C@]12CCc1ccoc1</smiles>

(1)

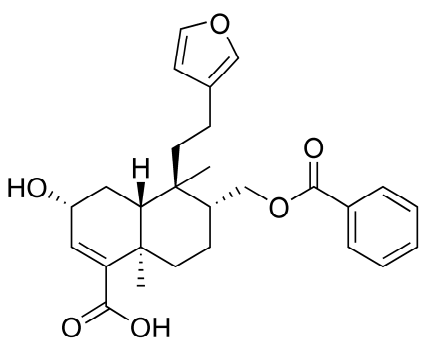

(2)

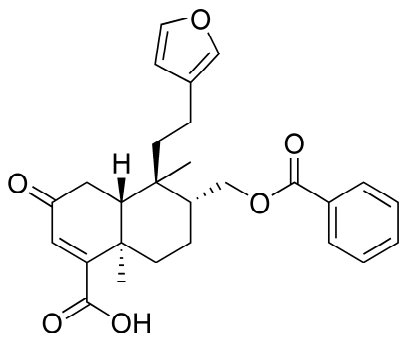

(3)<smiles>C[C@H]1CC[C@H]2C(C(=O)O)=CC(OC(=O)c3ccccc3)C[C@]2(CCc2ccoc2)[C@H]1C</smiles>

(4)

Figure 3 Anti-inflammatory diterpenoids isolated from $D$. polyandra

It could not be ruled out that other constituents within $D$. polyandra might be playing a supportive role for the observed antiinflammatory activity either through some additive anti-inflammatory effects or through effects on the distribution or clearance of the active diterpenoid compounds. Additional chemical analyses undertaken of 'less-active' fractions revealed the presence of a number of prenylated and non-prenylated flavonoids (53). Interestingly, a kaempferol derivative isolated in that study has been previously reported as an inhibitor of carrageenan-induced hind paw oedema and shown to be a potent anti-nociceptive agent in mice (54). The flavonoid class of secondary metabolites and in particular derivatives containing prenylated side chains are consistent with other studies conducted on related species within the Dodonaea genus where similar compounds have been identified (55-57). One of the main features of these compounds is their lipophilicity. Lipophilic compounds tend to be transported across the skin or mucous membranes better than hydrophilic compounds and may therefore have the ability to have effects in the local tissues or to enter the circulation. The particular activities of the flavonoids isolated from D.polyandra remain to be explored, but prenylated flavonoids have been found to exert a variety of physiological effects due to their affinity for biological membranes and protein targets such as enzymes (58).

A direction this research is heading towards is the development of commercial medicinal products that contain or are derived from the plant products used in Kuuku I'yu traditional medicine. The discovery of the potent anti-inflammatory compounds from $D$. polyandra led to discussions with Kuuku I'yu traditional owners relating to the commercial prospects of such compounds and/or the extracts derived from the species. As part of this work is also centred on protecting Indigenous traditional knowledge, efforts were made to initiate protecting existing and new Intellectual Property via provisional patent applications in 2009 and subsequent Patent Co-operation Treaty (PCT) applications leading to National Phase Filing in 2012 in several countries including the United States, countries of the European Union, China and others (59). This process was a landmark achievement in the history of the research from several points of view. Firstly, recognition and protection of the traditional knowledge involved, acknowledgment of traditional owners as inventors including a deceased focal Kuuku I'yu ancestor. Most importantly the Chuulangun Aboriginal Corporation and University of South Australia are joint applicants of the patent which signifies the ongoing commitment that Western researchers have in ensuring Indigenous researchers and their community benefit equally from the research being conducted.

In the event of a saleable product being brought to market, how raw material will be supplied and processed is an obvious question that researchers have started investigating. In keeping with Indigenous ecological practices, the most fitting approach is to have raw plant material bush harvested by members of the Indigenous community, as opposed to controlled cultivation methods. This approach would create employment opportunities for the community to be involved in the field work, aligning with other aims and desirable outcomes for our research. A similar commercialisation case to this exists between Jarlmadangah Burru Aboriginal Corporation and Eskitis Institute - Griffith University, Queensland related to a plant with pain relieving properties known as the Marjala plant (mentioned earlier) (42). In 2008, both parties entered into a commercialisation agreement with biotechnology 
company Avexis. Whilst our research does not yet have a commercial industry partner, a point of difference between the two cases is that the Avexis agreement outlines the opportunity for Jarlmadangah Burru Aboriginal Corporation to cultivate and supply raw material, instead of bush harvest.

From the perspective of Kuuku I'yu traditional owners horticulture and cultivation style practices are not consistent with Indigenous land management practice and philosophy. Plant materials need to be wild harvested by people who have been authorised under Indigenous governance and law in order for the medicine to have the proper medicinal effect. Further, unauthorised use of particular plant medicines could contravene Indigenous law and could have negative consequences in terms of intergenerational transfer of traditional knowledge.

The significant number of plants used by Kuuku I'yu people and their potential to be screened in a vast number of disease models suggests that there is a long future for this collaboration. As such, it is envisaged that new opportunities to protect intellectual property will arise. Aside from patents, future intellectual property protection strategies may include looking at the appropriateness of trademarking. Trademarks may allow a product to be linked to a particular culture and geographical region. One issue which arises in the patenting process is the concern that other communities may use $D$. polyandra for different purposes or use different parts of the plant. Depending on the scope of claims granted within the patent, this could prevent any other communities from exploring the full scope of their own commercial projects related to that species. Chuulangun Aboriginal Corporation is also exploring other options for protecting Indigenous knowledge about natural resources more broadly in a way that recognises the geographical region and the natural resources and people that belong to it. This is one of the many challenges and learning curves faced with this type of research, where Western intellectual property laws have not been developed to properly protect Indigenous intellectual property (35).

Dodonaea polyandra fits within a unique subgroup of plants whereby it grows as separate and distinct male and female individual plants, termed dioecious. This is in contrast to majority of flowering plants which are bisexual, that is containing a flower with both male and female reproductive units (60). During collections made on Northern Kaanju homelands, raw material from a positively identified male individual was obtained and brought back to the laboratory for chemical characterisation. Initial work indicated that the constituents within this male sample were significantly different to those previously identified during bioactivity-guided fractionation. On this occasion bioactivity did not guide fractionation of the plant constituents, instead we aimed to identify the major components present. The study led to isolation and structural elucidation of several labdane diterpenoids, a subgroup of the diterpenoid class that is biosynthetically related to the clerodane type mentioned earlier (61). In the same manner that the prenylated flavonoids appear to be common in the genus Dodonaea, labdane diterpenoids have been regularly identified in other species of the genus (62-64). While the bioactivity of this sample remains to be tested, the chemistry of this male individual is quite unique. Of interest was that the clerodane diterpenoids identified previously were not detected in this male individual, giving the possibility of distinct differences between male and female individuals of this species. A novel labdane diterpenoid containing a rare seven-membered cyclic ether functionality was found (61). Analogous compounds have only been yielded via synthetic methods (65) and a brominated derivative identified from a marine algae (66). Hence, the discovery of such a molecule from a terrestrial source is of great significance. It also exemplifies the significance of Australian medicinal plants as an untapped source of novel chemical scaffolds. Whilst the traditional use of many Australian plants have been published in sources including Aboriginal pharmacopoeias and other books of similar nature $(13,67)$, much of the Western scientific properties of these plants remains to be unravelled.

The focus of the most recent work has involved probing the mechanism of action of the clerodane diterpenoid compounds formerly identified. No work from this study has been published at the time of writing and therefore discussion will be kept to a general nature. The compounds were tested for inhibition of cyclooxygenase (COX)-1 and 2 enzyme activity. However, results from this test was negative implying the compounds were not COX inhibitors. Given the complex nature of the inflammation process and a lack of knowledge regarding the mechanisms of the anti- 
inflammatory compounds, initial work has focused on determining what effect the compounds have on cytokine production in both immunological and skin cells. The chosen direction is a reflection of the in vivo model used for guiding the initial activity where immune cells (eg. monocyte/macrophage) and skin cells (eg. keratinocyte) act in concert to release cytokines that are known to give rise to the inflammatory response following induction (with TPA). To date, data from both in vitro and in vivo experimental conditions suggest that several pro-inflammatory cytokines and cytokines involved in skin proliferation processes are implicated. Protein kinase $\mathrm{C}$ which is activated by TPA (68) and responsible for transducing the inflammatory response cascade in the TPA-induced mouse ear oedema model has been ruled out as a target, with negative results obtained from screening one of the active compounds against all isoforms of this kinase. Time-response data obtained in earlier in vivo work suggests that the compounds are acting at an early stage of the inflammatory response, as indicated by a shallower slope of the data line (Figure 4) (69). In this particular animal model steroid-like compounds often give similar patterns of data, in contrast to NSAID compounds which often show a delayed response and hence a steeper slope in the early stages (ie. Treatment and control data overlap until after several hours have passed). Continuing work in this area may look at exploring gene expression profiles which might help to shed light on the proinflammatory genes affected when cells are treated with the clerodane diterpenoids.

Efforts to explore the development of $D$. polyandra as a commercial medicinal product have included the preparation of prototype formulations containing both a crude extract and pure 'active' compounds. This work (unpublished) has involved the use of in vitro techniques aimed at optimising the characteristics of an appropriate semi-solid dosage form including physicochemical stability and drug release with subsequent confirmation in vivo for bioactivity. These prototypes have demonstrated some success in mouse studies and are now progressing towards being tested in different models of skin inflammation to assess their efficacy and 3D skin models to assess toxicity and irritancy.

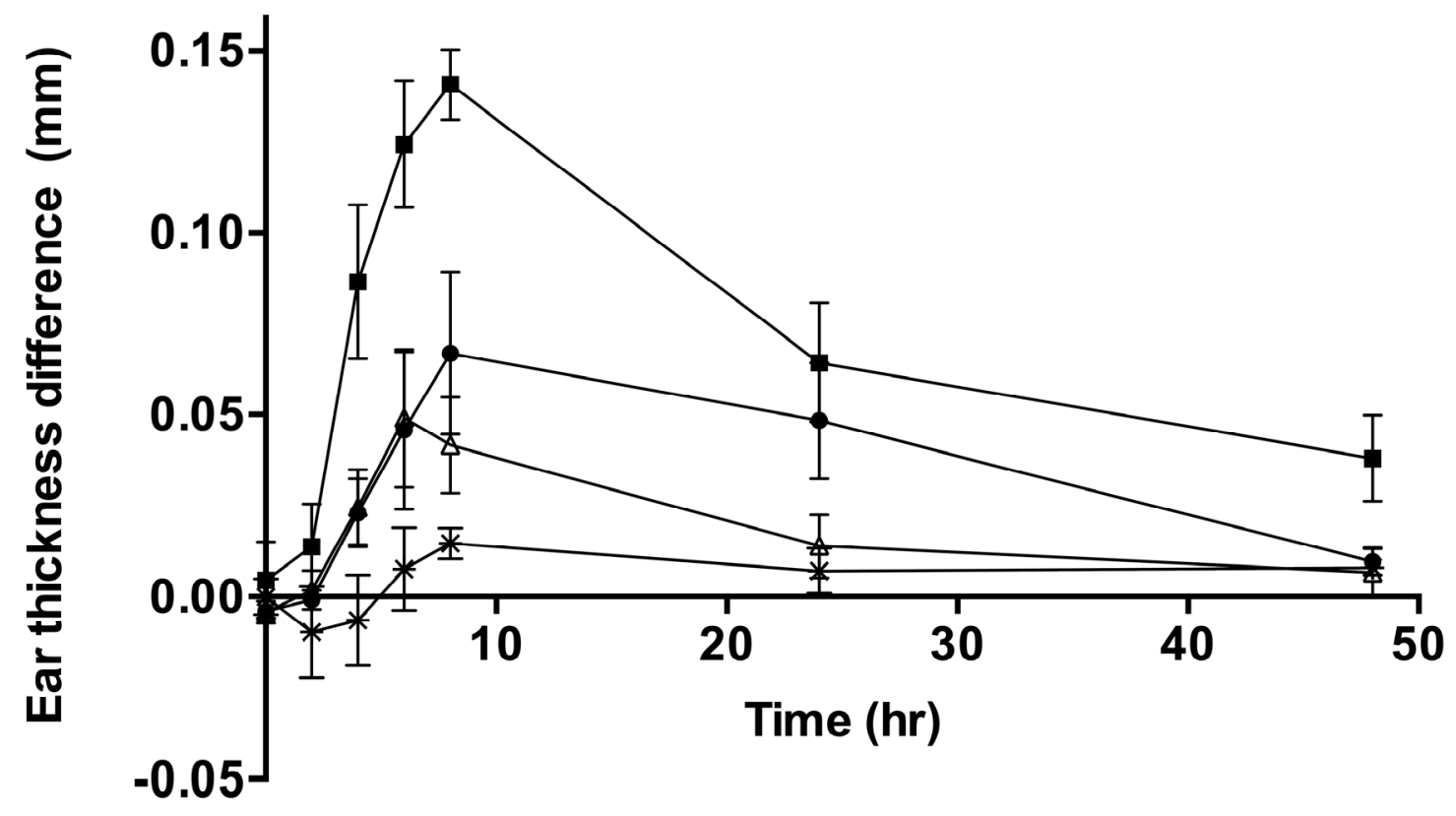

Figure 4 Time-response data of active compounds 2 and 4 (from Figure 3) showing slope of treatment curves shallower than TPA control curve, indicating compounds are acting on the early response of the inflammatory process. ( = TPA control $(2.5 \mu \mathrm{g} / \mathrm{ear}), \triangle=$ compound $2(0.88 \mu \mathrm{mol} / \mathrm{ear}), \bullet=$ compound $4(0.9 \mu \mathrm{mol} / \mathrm{ear})$ and $\times=$ betamethasone-17,21-dipropionate $(0.9 \mu \mathrm{mol} / \mathrm{ear}))$. 
It must be recognised in the Western scientific testing of plants used in traditional medicine that there are often some fundamental limitations in the conclusions that can be drawn. Placing a plant extract into a laboratory-based test removes it from the context in which it is used in traditional medicine including the spiritual and cultural aspects of use. A plant extract produced in a laboratory will never contain the exact blend of plant chemicals that will be available when the plant is being used directly by a person in their traditional medicine system. Aspects of plant compound absorption and metabolism are very difficult to replicate in the laboratory and are completely absent in most initial screening tests to identify plants of interest from a Western scientific perspective. While we have gone some way in gaining a Western scientific understanding of the medicinal activity of Dodonaea polyandra, and how this complements Kuuku I'yu understandings of the plant's effects, there is still the need for more detailed studies of how the plant actually works in the traditional use setting. Often our research priorities have been driven by the potential commercial development of the plant extracts and the need to meet expectations of potential commercial partners and medicine regulatory authorities.

\section{CONCLUSION}

Whilst this collaboration has developed a model which describes one approach to be used in conducting medicinal plant research involving Indigenous partners, we are reminded that the process should be constantly evolving and adapted to ensure continued growth of research outcomes.

In terms of the broader picture in the investigation of Australian Aboriginal medicinal plants, there is no time like the present. Australia is positioned as one of the megadiverse countries in the world. There are species growing in areas occupied by Indigenous populations which have had no Western-scientific evaluations conducted on them. A number of Indigenous groups are examining ways to develop their medicinal plant resources that will provide opportunities to ensure the future existence of their people and culture. We have described some of the Western scientific outcomes using a research model where Aboriginal people actively participate as researchers in locally initiated and driven medicinal plant research. As the project moves forward it is envisaged that this will lead to the development of novel plant-based commercial products which will help to facilitate the reoccupation of traditional homelands via community operated business enterprises and sustainable management of these lands. The blending of Indigenous and Western scientific methodology is serving as a bridge to ensure the success of this vision. No singular, detailed model or approach exists for addressing these issues and any way forward will need to be developed in conjunction with Aboriginal people in particular places in a local context. Models for Aboriginal participation and developing cross-cultural collaboration will inevitably vary from place to place. If there is one aspect of any future model which should be inherent in its design, it is that there continues to be learning from both sides.

\section{ACKNOWLEDGEMENTS}

The authors thank the Chuulangun Aboriginal Corporation for their ongoing commitment to the collaborative research projects. The authors indicate that there are no conflicts of interest regarding the content of this article.

\section{REFERENCES}

1. Rasmussen M, Guo X, Wang Y, Lohmueller KE, Rasmussen S, Albrechtsen A, et al. An Aboriginal Australian Genome Reveals Separate Human Dispersals into Asia. Science. 2011 October 7, 2011;334(6052):94-8.

2. Gammage B. The biggest estate on earth: how Aborigines made Australia. Crows Nest, N.S.W.: Allen \& Unwin; 2011.

3. Bird-Rose D. Nourishing Terrains. Australian Aboriginal Views of Landscape and Wilderness. In: Australian Heritage Commission, editor. Canberra1996.

4. Hallam S. Fire and hearth: a study of Aboriginal usage and European usurpation in south-western Australia. In: Australian Institute of Aboriginal Studies, editor. Canberra1975.

5. Bowman D. The impact of Aboriginal landscape burning on the Australian biota. New Phytologist. 1998;140:385-410.

6. Yibarbuk D, Whitehead P, Russell-Smith J, Jackson D, Godjuwa C, Fisher A, et al. Fire ecology and Aboriginal land management in central Arnhem Land, northern Australia: a tradition of ecosystem management. J Biogeogr. 2001;28:325-43.

7. Smith B. "All been washed away now": Tradition, change and Indigenous knowledge in a Queensland Aboriginal land claim. In: Pottier J, Bicker A, Sillitoe P, editors. Negotiating Local Knowledge: Power and Identity in Development. 
London: Pluto Press; 2003.

8. Kelly G. Report on Threats to the Practice and Transmission of Traditional Knowledge-Regional Report: Asia and Australia, Phase II of the Composite Report on the Status and Trends Regarding the Knowledge, Innovation and Practices of Indigenous Peoples and Local Communities relevant to the Conservation and Sustainable Use of Biodiversity. In: United Nations, editor. 2005.

9. Burgess C, Johnston F, Bowman D, Whitehead P. Healthy Country: Healthy People? Exploring the health benefits of Indigenous natural resource management. Aust NZ J Publ Health. 2005;29:117-22.

10. Maffi L. On Biocultural Diversity. Linking Language, Knowledge, and the Environment. Washington: Smithsonian Institute Press; 2001.

11. Clarke P. Aboriginal healing practices and Australian bush medicine. J Anthropol Soc Sth Aust. 2008;33.

12. Latz P. Bushfires and Bushtucker: Aboriginal Plant Use in Central Australia. Alice Springs: IAD Press; 1995.

13. Aboriginal Communities of the Northern Territory of Australia; Conservation Commission of the Northern Territory. Traditional Aboriginal Medicines in the Northern Territory of Australia. Australia: Conservation Commission of the Northern Territory; 1993. p. 651.

14. Clarke P. Aboriginal People and Their Plants. NSW: Rosenberg Publishing Pty. Ltd; 2007.

15. Chapman AD. Numbers of living species in Australia and the world. 2nd ed. Australia: Australian Governent; 2009.

16. Crisp MD, Laffan S, Linder HP, Monro A. Endemism in the Australian flora. J Biogeogr. 2001;28(2):183-98.

17. Ralph-Flint J. Cultural borrowing and sharing: Aboriginal bush medicine in practice. Aust $\mathrm{J}$ Holist Nurs. 2001;8(1):43-6.

18. Gurib-Fakim A. Medicinal plants: Traditions of yesterday and drugs of tomorrow. Mol Aspects Med. 2006;27:1-93.

19. Maher P. A review of 'traditional' Aboriginal health beliefs. Aust J Rural Health. 1999;7:229-36.

20. Onus F, editor The on-going impacts of racist policies of the past. Townsville International Women's Conference - Australia; 2002; Townsville.

21. Soejarto DD, Fong HHS, Tan GT, Zhang HJ, Ma CY, Franzblau SG, et al. Ethnobotany/ethnopharmacology and mass bioprospecting: Issues on intellectual property and benefit-sharing. J Ethnopharmacol. 2005;100:1522.

22. The Lowitja Institute. Supporting Aboriginal communities to do research 2012 [viewed 05/03/13]. Available from: http://www.lowitja.org.au/supporting-aboriginalcommunities-do-research.
23. Bonn Guidelines on Access to Genetic Resources and Fair and Equitable Sharing of the Benefits Arising Out of Their Utilization. Montreal: Secretariat of the Convention on Biological Diversity; 2002.

24. Convention on Biological Diversity. Nagoya Protocol on Access to Genetic Resources and the Fair and Equitable Sharing of Benefits Arising from their Utilization to the Convention on Biological Diversity. Canada: Secretariat of the Convention on Biological Diversity; 2011.

25. Australian Institute of Aboriginal and Torres Strait Islander Studies. Guidelines for Ethical Research in Australian Indigenous Studies. Canberra, Australia2011.

26. Agrawal A. Dismantling the Divide Between Indigenous and Scientific Knowledge. Dev Change. 1995;26(3):413-39.

27. Smith BR. 'Indigenous' and 'Scientific' knowledge in Central Cape York Peninsula. In: Sillitoe P, editor. Local Science Vs Global Science: Approaches to Indigenous Knowledge in International Development: Berghahn Books; 2007.

28. Collins DJ, Culvenor CCJ, Lamberton JA, Loder JW, Prices JR. Plants for Medicines: A Chemical and Pharmacological Survey of Plants in the Australian Region: CSIRO Publishing, Melbourne; 1990.

29. Laird S, Monagle C, Johnston S. Queensland Biodiscovery Collaboration The Griffith University AstraZeneca Partnership for Natural Product Discovery. In: Department of the Environment W, Heritage and the Arts, editor. Australia2008.

30. Palombo E, Semple S. Antibacterial activity of traditional Australian medicinal plants. J Ethnopharmacol. 2001;77:151-7.

31. Pennacchio M, Syah Y, Ghisalberti E, Alexander E. Cardioactive iridoid glycosides from Eremophila species. Phytomedicine. 1997;4:32530.

32. Rogers KL, Grice ID, Griffiths LR. Inhibition of platelet aggregation and 5-HT release by extracts of Australian plants used traditionally as headache treatments. Eur J Pharm Sci. 2000;9:355-63.

33. Semple SJ, Reynolds GD, O'Leary MC, Flower RLP. Screening of Australian medicinal plants for antiviral activity. J Ethnopharmacol. 1998;60:16372.

34. Tan A, Sze D. Indigenous herbs and cancer. J Complement Med. 2008;7:48-50.

35. Claudie DJ, Semple SJ, Smith NM, Simpson BS. Ancient but new. Developing locally-driven enterprises based on traditional medicines in "Kuuku I'yu" (Northern Kaanju homelands, Cape York, Queensland, Australia). In: Drahos P, Frankel S, editors. Indigenous Peoples' Innovation: IP Pathways to development. Canberra: ANU epress; 2012.

36. Australian Human Rights Commission. Social 
Justice Report 2010. 2010. p. 130.

37. Altman J. Sustainable development options on Aboriginal land: The hybrid economy in the twenty-first century, Discussion Paper 226/2001, In: Centre for Aboriginal Economic Policy Research, editor. Canberra: Australian National University; 2001.

38. Brouwer N, Liu Q, Harrington D, Kohen S, Vemulpad S, Jamie J, et al. An Ethnopharmacological Study of Medicinal Plants in New South Wales. Molecules. 2005;10:125262.

39. Packer J, Gaikwad J, Harrington D, Ranganathan S, amie J, Vemulpad S. Medicinal Plants of New South Wales (NSW), Australia. In: Singh RJ, editor. Medicinal Crops. Boca Raton, FL: CRC Press LLC; 2011.

40. Gaikwad J, Khanna V, Vemulpad S, Jamie J, Kohen J, Ranganathan S. CMKb: a web-based prototype for integrating Australian Aboriginal customary medicinal plant knowledge. BMC Bioinformatics. 2008;9(Suppl 12) S25.

41. Macquarie University Indigenous Bioresources Research Group. Indigenous Science Education Program [24/01/13]. Available from: http://web.science.mq.edu.au/groups/isep/.

42. Mills C, Carroll AR, Quinn RJ. Acutangulosides A-F, Monodesmosidic Saponins from the Bark of Barringtonia acutangula. J Nat Prod. 2005 2005/03/01;68(3):311-8.

43. Quinn R, Mills C, inventors; Griffith University, Jarlmadangah Buru Aboriginal Corporation, assignee. Analgesic compounds, extracts containing same and methods of preparation. US7618946 2009.

44. Smith BR, Claudie D. Developing a land and resource management framework for Kaanju homelands, central Cape York Peninsula. Discussion Paper 256. Centre For Aboriginal Economic Policy Research. Canberra: Australian National University; 2003.

45. de Young LM, Kheifets JB, Ballaron SJ, Young JM. Edema and cell infiltration in the phorbol ester-treated mouse ear are temporally separate and can be differentially modulated by pharmacologic agents. Agents Actions. 1989 1989/03/01;26(3-4):335-41. English.

46. Simpson B, Claudie D, Smith N, Wang J, McKinnon R, Semple S. Evaluation of the antiinflammatory properties of Dodonaea polyandra, a Kaanju traditional medicine. J Ethnopharmacol. 2010;132(1):340-3.

47. Simpson BS, Claudie DJ, Gerber JP, Pyke SM, Wang J, McKinnon RA, et al. In vivo activity of benzoyl ester clerodane diterpenoid derivatives from Dodonaea polyandra. J Nat Prod. 2011;74(4):650-7.

48. Calabrese EJ. Hormetic Dose-Response Relationships in Immunology: Occurrence, Quantitative Features of the Dose Response, Mechanistic Foundations and Clinical
Implications Crit Rev Toxicol. 2005;35:89-295.

49. Snijdewint FG, Kapsenberg ML, Wauben-Penris PJ, Bos JD. Corticosteroids class-dependently inhibit in vitro Th1- and Th2-type cytokine production. Immunopharmacol. 1995;29:93-101.

50. Morand E, Leech M. Glucocorticoid regulation of inflammation: the plot thickens. Inflamm Res. 1999;48(11):557-60.

51. Yeager M, Guyre P, Munck A. Glucocorticoid regulation of the inflammatory response to injury. Acta Anaesthesiol Scand. 2004;48(7):799-813.

52. Barnes PJ. Anti-inflammatory actions of glucocorticoids: molecular mechanisms. Clin Sci. 1998;94:557-72.

53. Simpson BS, Claudie DJ, Smith NM, Gerber JP, McKinnon RA, Semple SJ. Flavonoids from the leaves and stems of Dodonaea polyandra: A Northern Kaanju medicinal plant. Phytochemistry. 2011;72(14-15):1883-8.

54. Küpeli E, Yesilad E. Flavonoids with antiinflammatory and antinociceptive activity from Cistus laurifolius L. leaves through bioassayguided procedures. J Ethnopharmacol. 2007;112:524-30.

55. Niu H-M, Zeng D-Q, Long C-L, Peng Y-H, Wang Y-H, Luo J-F. Clerodane diterpenoids and prenylated flavonoids from Dodonaea viscosa. J Asian Nat Prod Res. 2010;12(1):7-14.

56. Sachdev K, Kulshreshtha DK. Flavonoids from Dodonaea viscosa. Phytochemistry. 1983;22(5):1253-6.

57. Wollenweber E, Roitman J. New reports on surface flavonoids from Chamaebatiaria (Rosaceae), Dodonaea (Sapindaceae), Elsholtzia (Lamiaceae), and Silphium (Asteraceae). Nat Prod Comm. 2007;2(4):385-9.

58. Botta B, Vitali A, Menendez P, Misiti D, Monache Giuliano D. Prenylated Flavonoids: Pharmacology and Biotechnology. Curr Med Chem. 2005;12(6):713-39.

59. Anti-inflammatory compounds 2011. http://patentscopewipoint/search/en/detailjsf?docI $\mathrm{d}=\mathrm{WO} 2011057332 \& \mathrm{recNum}=138 \& \operatorname{doc} A n=A U 20$ $10001502 \&$ queryString $=$ aquaculture $\& \max R e c=20$ 52.

60. Ainsworth C. Boys and Girls Come Out to Play: The Molecular Biology of Dioecious Plants. Ann Bot. 2000 August 1, 2000;86(2):211-21.

61. Simpson BS, Claudie DJ, Smith NM, McKinnon RA, Semple SJ. Rare, seven-membered cyclic ether labdane diterpenoid from Dodonaea polyandra. Phytochemistry. 2012;84:141-6.

62. Jefferies PR, Knox JR, Scaf B. The Chemistry of Dodonaea spp. VII ent-Labdanes from $D$. microzyga (Sapindaceae). Aust J Chem. 1974;27:1097-102.

63. Wabo $\mathrm{H}$, Chabert $\mathrm{P}$, Tane $\mathrm{P}$, Noté O, Tala $\mathrm{M}$, Peluso J, et al. Labdane-type diterpenes and flavones from Dodonaea viscosa. Fitoterapia. 2012;83(5):859-63.

64. Simone Quintana de O, Maria Tereza Rojo de A, 
Flora M, Izabella Thaís S, Thais Cristine Marques $\mathrm{S}$, Jorge Alejandro $\mathrm{P}$, et al. Isolation of three new ent-labdane diterpenes from Dodonaea viscosa Jacquin (Sapindaceae): Preliminary evaluation of antiherpes activity. Phytochem Lett. 2012;5(3):500-5.

65. Grant P, Liau H, Low K. Diterpene chemistry. V. Thallium(III) nitrate oxidations of exocyclic olefins. Aust J Chem. 1975;28(4):903-8.

66. Iliopoulou D, Mihopoulos N, Roussis V, Vagias C. New brominated labdane diterpenes from the red alga Laurencia obtusa. J Nat Prod. 2003 2012/02/16;66(9):1225-8.
67. Lassak EV, McCarthy T. Australian Medicinal Plants. Australia: New Holland Publishers; 2001. $240 \mathrm{p}$.

68. Kontny E, Ziółkowska M, Ryzewska A, Maśliński W. Protein kinase c-dependent pathway is critical for the production of pro-inflammatory cytokines (TNF-alpha, IL-1beta, IL-6). Cytokine. 1999;11(11):839-48.

69. Murakawa M, Yamaoka K, Tanaka Y, Fukuda Y. Involvement of tumor necrosis factor (TNF)- $\alpha$ in phorbol ester 12-O-tetradecanoylphorbol-13acetate (TPA)-induced skin edema in mice. Biochem Pharmacol. 2006;71(9):1331-6. 